\title{
Neuroanatomical changes in white and grey matter after sleeve gastrectomy
}

\author{
Andréanne Michaud $^{\mathrm{a}, *}$, Mahsa Dadar ${ }^{\mathrm{b}}$, Mélissa Pelletier $^{\mathrm{a}}$, Yashar Zeighami ${ }^{\mathrm{b}}$, \\ Isabel Garcia-Garcia ${ }^{c}$, Sylvain Iceta ${ }^{\mathrm{a}}$, Yvonne Yau ${ }^{\mathrm{b}}$, Mélanie Nadeau ${ }^{\mathrm{a}}$, Simon Marceau ${ }^{\mathrm{d}}$, \\ Laurent Biertho $^{\mathrm{d}}$, André Tchernof ${ }^{\mathrm{a}}$, D. Louis Collins ${ }^{\mathrm{b}}$, Denis Richard ${ }^{\mathrm{a}}$, Alain Dagher ${ }^{\mathrm{b}, * *}$ \\ ${ }^{a}$ Centre de recherche de l'Institut universitaire de cardiologie et de pneumologie de Québec, Université Laval, Québec, Canada \\ ${ }^{\mathrm{b}}$ Montreal Neurological Institute, Department of Neurology and Neurosurgery, McGill University, 3801 University Street, Montreal, QC, H3A 2B4, Canada \\ ${ }^{\mathrm{c}}$ Department of Clinical Psychology and Psychobiology, University of Barcelona Barcelona, Spain \\ d Département de chirurgie, Institut universitaire de cardiologie et de pneumologie de Quebec, Université Laval, Québec, Canada
}

\section{A R T I C L E I N F O}

\section{Keywords:}

Voxel-based morphometry

White matter

Grey matter

Bariatric surgery

Inflammation

Lipopolysaccharide-binding protein

\begin{abstract}
A B S T R A C T
Background: MRI studies show that obese adults have reduced grey matter (GM) and white matter (WM) tissue density as well as altered WM integrity. Bariatric surgery can lead to substantial weight loss and improvements in metabolic parameters, but it remains to be examined if it induces structural brain changes. The aim of this study was to characterize GM and WM density changes measured with MRI in a longitudinal setting following sleeve gastrectomy, and to determine whether any changes are related to inflammation and cardiometabolic blood markers.

Methods: 29 participants with obesity (age: $45.9 \pm 7.8$ years) scheduled to undergo sleeve gastrectomy were recruited. High-resolution T1-weighted anatomical images were acquired 1 month prior to as well as 4 and 12 months after surgery. GM and WM densities were quantified using voxel-based morphometry (VBM). Circulating lipid profile, glucose, insulin and inflammatory markers (interleukin-6, C-reactive protein and lipopolysaccharidebinding protein) were measured at each time point. A linear mixed effect model was used to compare brain changes before and after SG, controlling for age, sex, initial BMI and diabetic status. To assess the associations between changes in adiposity, metabolism and inflammation and changes in GM or WM density, the mean GM and WM densities were extracted across all the participants using atlas-derived regions of interest, and linear mixed-effect models were used.

Results: As expected, weight, BMI, waist circumference and neck circumference significantly decreased after SG compared with baseline ( $\mathrm{p}<0.001$ for all). A widespread increase in WM density was observed after surgery, particularly in the cerebellum, brain stem, cerebellar peduncle, cingulum, corpus callosum and corona radiata ( $\mathrm{p}$ $<0.05$, after FDR correction). Significant increases in GM density were observed 4 months after SG compared to baseline in several brain regions such as the bilateral occipital cortex, temporal cortex, postcentral gyrus, cerebellum, hippocampus and insula as well as right fusiform gyrus, right parahippocampal gyrus, right lingual gyrus and right amygdala. These GM and WM increases were more pronounced and widespread after 12 months and were significantly associated with post-operative weight loss and the improvement of metabolic alterations. A linear mixed-effect model also showed associations between post-operative reductions in lipopolysaccharidebinding protein, a marker of inflammation, and increased WM density. To confirm our results, we tested whether the peak of each significant region showed BMI-related differences in an independent dataset (Human Connectome Project). We matched a group of individuals who were severely obese with a group of individuals who were lean for age, sex and ethnicity. Severe obesity was associated with reduced WM density in the brain stem and cerebellar peduncle as well as reduced GM density in cerebellum, regions that significantly changed after surgery ( $\mathrm{p}<0.01$ for all clusters).

Conclusions: Bariatric surgery-induced weight loss and improvement in metabolic alterations is associated with widespread increases in WM and GM densities. These post-operative changes overlapped with baseline brain differences between participants who were severely obese and those who were normal-weight in a separate dataset, which may suggest a recovery of WM and GM alterations after bariatric surgery.
\end{abstract}

\footnotetext{
* Corresponding author. Centre de recherche de l'IUCPQ, Université Laval, 2725 Chemin Ste-Foy, Québec (Québec), G1V 4G5, Canada.

** Corresponding author. Montreal Neurological Institute McGill University, 3801 University Street, Montreal, Quebec, H3A 2B4, Canada.

E-mail addresses: andreanne.michaud@fsaa.ulaval.ca (A. Michaud), alain.dagher@mcgill.ca (A. Dagher).
} 


\section{Introduction}

Adding to the well-known metabolic alterations related to obesity such as insulin resistance, dyslipidemia, elevated blood pressure and chronic low-grade inflammation (Tchernof and Despres, 2013; Despres and Lemieux, 2006), epidemiological studies and recent meta-analyses reported that moderate lifetime overweight/obesity is related to an increased risk of cognitive impairment and incident dementia (Albanese et al., 2017; Prickett et al., 2015; Pedditizi et al., 2016). Brain alterations induced by obesity may underlie the link between obesity and cognitive dysfunction (Walther et al., 2010; Zhang et al., 2018). Thus, a better understanding of the structural brain changes associated with obesity and body weight fluctuation in humans is of particular relevance.

MRI studies show that adults with obesity have reduced grey matter (GM) and white matter (WM) tissue density. For instance, our recent neuroimaging coordinate-based meta-analysis on voxel-based morphometry (VBM) demonstrated that obesity is associated with reduced GM volume in discrete brain regions, namely the ventromedial prefrontal cortex, cerebellum and portions of temporal and parietal lobes (Garcia-Garcia et al., 2019). A study in participants with morbid obesity undergoing bariatric surgery found widespread cortical and subcortical GM atrophy prior to surgery (Tuulari et al., 2016). In a cross-sectional study, obesity was also associated with a greater degree of WM atrophy, with an estimated increase in brain age of 10 years (Ronan et al., 2016). There is a possible link between obesity-related GM atrophy and dementia, as the BMI-GM atrophy correlation is also seen in individuals with mild cognitive impairment and Alzheimer's Disease (Ho et al., 2010).

Findings on WM structure in obesity are less clear (Kullmann et al., 2015; Alfaro et al., 2018). Some studies report a positive association between obesity and WM density in frontal, temporal and parietal regions (Walther et al., 2010; Haltia et al., 2007), while other studies find a negative association in basal ganglia and corona radiata (Raji et al., 2010). WM hyperintensities, which are markers of central nervous system ischemic disease, have also been observed in greater numbers in individuals with obesity (Kullmann et al., 2015; Alfaro et al., 2018; Lampe et al., 2019). Studies using diffusion tensor imaging have shown a loss of WM integrity linked to cognitive impairments in participants with obesity (Zhang et al., 2018; Kullmann et al., 2016; Karlsson et al., 2013; Verstynen et al., 2013).

The mechanism linking obesity with reductions in brain volume measured by MRI remains largely unknown. Animal studies suggest that chronic inflammation associated with obesity can lead to adverse effects on brain tissue (Thaler and Schwartz, 2010; Guillemot-Legris and Muccioli, 2017). Indeed, adipose tissue dysfunction observed with obesity, especially visceral adiposity, results in increased levels of circulating inflammatory mediators that may alter the function of many organs, including the brain (Verstynen et al., 2013). Recent discoveries in humans also point to the chronic, low-grade inflammation and vascular risk factors as potential mechanisms to explain obesity-induced WM alterations (Alfaro et al., 2018; Lampe et al., 2019; Verstynen et al., 2013; Guillemot-Legris and Muccioli, 2017; Moreno-Navarrete et al., 2017; Bettcher et al., 2013). Changes in gut hormones and microbiota associated with obesity have also been proposed as potential mechanisms to explain obesity-induced brain alterations (Torres-Fuentes et al., 2017). However, it is unclear if these brain changes are permanent or whether they can be reversed after weight loss.

Bariatric surgery represents an interesting approach to address these questions, since it allows the examination of the effects of sustained weight loss and long-term metabolic improvements on the brain in a longitudinal setting (Schauer et al., 2012; Gloy et al., 2013; Sjostrom et al., 2012). Growing evidence shows improvement in cognitive functions after bariatric surgery (Alosco et al., 2014; Handley et al., 2016). However, only a few structural MRI studies examined changes in GM and WM densities after bariatric surgery (Tuulari et al., 2016; Rullmann et al., 2018; Zhang et al., 2016). Tuulari et al. (2016) were the first to show global increase in WM density and limited increase in GM density (occipital and temporal regions) 6 months after bariatric surgery using VBM. Zhang et al. (2016) observed increased GM and WM densities as well as improved WM integrity in regions involved in food intake control and cognitive-emotion regulation 1 month following sleeve gastrectomy (SG) compared to baseline. A recent study found widespread WM and GM density changes in all cortical and subcortical structures as well as the brainstem and cerebellum 1 year after gastric bypass surgery (Rullmann et al., 2018). Several mechanisms have been suggested to explain the effects of bariatric surgery on brain structure and function. These potential mechanisms include improvements of glucose and insulin homeostasis, reduction of inflammatory cytokines secreted by adipose tissues (adipokines), improvements in cerebral blood flow and changes in incretin/gut peptide secretion or products of the microbiota that may impact the brain (Hankir et al., 2018, Hankir et al., 2020; Nota et al., 2020). However, very few studies have examined these mechanisms in humans and most of these studies were conducted with Roux-en-Y gastric bypass (Hankir et al., 2018, Hankir et al., 2020). A better understanding of the link between cardiometabolic variables, inflammatory markers and brain structural changes is needed.

In the present longitudinal study, we aimed to characterize GM and WM density changes 4 months and 12 months after SG, comparing preand post-surgery and to determine whether these changes are associated with inflammation and cardiometabolic markers. We tested the hypothesis that bariatric surgery and the associated weight loss induce recovery of GM and WM density, and that these changes are related to improvements in inflammatory and metabolic variables.

\section{Materials and methods}

\subsection{Participant recruitment}

The study sample included 29 participants with severe obesity (8 men, 21 women; mean age $=45.9 \pm 7.8$ years; mean $\mathrm{BMI}=44.1 \pm 4.6$ $\mathrm{kg} / \mathrm{m}^{2}$ ) scheduled to undergo SG at the Institut universitaire de cardiologie et de pneumologie de Québec. Twenty-seven participants completed the experiments both pre-surgery and 4 months after SG. Among those participants, we also tested 17 participants 12 months after surgery. Inclusion criteria were the following: 1) women or men with a BMI $\geq 35 \mathrm{~kg} / \mathrm{m}^{2}$ who require surgery and who meet the NIH Guidelines for bariatric surgery (Gastrointestinal surgery, 1992); 2) age between 18 and 60 years. Exclusion criteria were the following: 1) $\mathrm{BMI}<35 \mathrm{~kg} / \mathrm{m}^{2} ; 2$ ) age under 18 or over 60 years; 3) any uncontrolled medical, surgical, neurological or psychiatric condition; 4) liver cirrhosis or albumin deficiency; 5) any medication that may affect the central nervous system; 6) pregnancy; 7) substance or alcohol abuse; 8) previous gastric, oesophageal, brain or bariatric surgery; 9) gastro-intestinal inflammatory diseases or gastro-intestinal ulcers; 10) severe food allergy; and 11) contraindications to MRI (implanted medical device, metal fragment in body, or claustrophobia). The Research Ethics Committee of the Centre de recherche de l'Institut universitaire de cardiologie et de pneumologie de Québec approved the study. All participants provided written informed consent to participate in the study.

\subsection{Surgical procedures}

All patients were operated laparoscopically. A $250 \mathrm{~cm}^{3}$ vertical SG starting $5 \mathrm{~cm}-7 \mathrm{~cm}$ from the pylorus to the Hiss angle was performed using a 34-44 French Bougie for guidance, to create a gastric tube (Biertho et al., 2016). The greater curvature and fundus of the stomach were removed.

\subsection{Study design and experimental procedures}

The current study is part of a larger study on the effects of restrictive and/or malabsorptive bariatric procedures on appetitive behavior. 
Participants were studied approximately 1 month prior to as well as 4, 12 and 24 months post-surgery. At each study visit, participants underwent a physical examination including measurement of blood pressure and fasting blood biochemistry. During the MRI sessions, participants underwent resting state functional MRI, task state functional MRI for foodcue reactivity, and anatomical T1-weighted MRI. For this report on structural brain changes after SG, only results from T1-weighted anatomical images prior to and 4 and 12 months after surgery are presented. The MRI sessions were performed on the morning (started between 9:00 and 10:30am) of each visit. Participants were asked to fast for $12 \mathrm{~h}$ before the scanning session and received a standardized beverage meal ( $237 \mathrm{ml}$, Boost original, Nestle Health Science) $1 \mathrm{~h}$ before the MRI session to control for hunger level during the fMRI task. The standardized beverage contained a total of $240 \mathrm{kcal}, 41 \mathrm{~g}$ of carbohydrates, $10 \mathrm{~g}$ of proteins and $4 \mathrm{~g}$ of lipids. It was consumed over a 5 -min period. Before each MRI session, body weight and height were measured using standardized procedures to calculate BMI $\left(\mathrm{kg} / \mathrm{m}^{2}\right)$ as well as percentage of excess weight loss (\%EWL) and percentage of total weight loss (\%TWL). The \%EWL was calculated using total pre-operative weight, postoperative weight, and ideal body weight (IBW) for a BMI of $23 \mathrm{~kg} / \mathrm{m}^{2}$ as previously used (Biertho et al., 2010). Waist circumference and neck circumference were also measured at each visit using standardized procedures. At each visit, eating behaviors were assessed using various questionnaires: the Three Factor Eating Questionnaire (TFEQ) (Stunkard and Messick, 1985), the Binge Eating Scale (BES) (Brunault et al., 2016), the Yale Food Addiction Scale 2.0 (YFAS) (Brunault et al., 2017), the Power of Food Scale (PFS) (Lowe et al., 2009), and the Food Craving Questionnaire (FCQ) (Nijs et al., 2007). Hunger levels were rated before and after the MRI session using a visual analogue scale (VAS) with the left anchor "Not hungry at all" and the right anchor "Very Hungry".

\subsection{Plasma lipid profile, glucose homeostasis, and inflammatory markers}

Blood samples were collected on the morning of each visit after a 12-h fast in EDTA-coated tubes or serum clot activator tubes. All samples were immediately placed at $4{ }^{\circ} \mathrm{C}$ and then centrifuged and stored at $-80{ }^{\circ} \mathrm{C}$. Plasma insulin levels were measured using chemiluminescence immunoassay and plasma glucose levels were measured using the hexokinase method (Michaud et al., 2017). The homeostasis model assessment insulin resistance (HOMA-IR) index was calculated (Matthews et al., 1985). Cholesterol and triglyceride levels in serum and lipoprotein fractions were measured with a Siemens Dimension Vista 1500 using enzymatic methods. Plasma interleukin (IL)-6 and lipopolysaccharide-binding protein (LBP) levels were measured by commercially available enzyme-linked immunosorbent assay (R\&D Systems, Minneapolis, MN and HyCult Biotechnology, Huden, the Netherlands, respectively) (Moreno-Navarrete et al., 2017; Michaud et al., 2012). Plasma CRP concentrations were measured using the high-sensitivity immunonephelometric assay.

\subsection{T1-weighted MRI acquisition}

T1-weighted three-dimensional (3D) turbo field echo images were acquired at the initial visit, 4 months, and 12 months after surgery using a 3T whole-body MRI scanner (Philips, Ingenia, Philips Medical Systems) equipped with a 32-channel head coil at the Centre de recherche de l'Institut universitaire de cardiologie et pneumologie de Québec. The following parameters were used: 176 sagittal $1.0 \mathrm{~mm}$ slices, repetition time/echo time $(\mathrm{TR} / \mathrm{TE})=8.1 / 3.7 \mathrm{~ms}$, field of view $(\mathrm{FOV})=240 \times 240 \mathrm{~mm}^{2}$, and voxel size $=1 \times 1 \times 1 \mathrm{~mm}$.

\subsection{Voxel-based morphometry measurements}

The T1-weighted structural scan of each participant was used to measure voxel-based morphometry. GM and WM densities were assessed from each T1-weighted MRI using a standard VBM pipeline
(Garcia-Garcia et al., 2019). The preprocessing steps were the following: 1) image denoising (Coupe et al., 2008); 2) intensity non-uniformity correction (Sled et al., 1998); and 3) image intensity normalization into range (0-100) using histogram matching. Images were then first linearly (using a nine-parameter rigid registration) and then nonlinearly registered to an average brain template (MNI ICBM152) as part of the ANIMAL software (Collins et al., 1994) and segmented into GM, WM and cerebrospinal fluid images. These steps remove global differences in the size and the shape of individual brains and transform individual WM or GM density maps to the standardized MNI ICBM152 template space. VBM analysis was performed using MNI MINC tools (http://www.bic.mni.mc gill.ca/ServicesSoftware/MINC) to generate WM and GM density maps representing the local WM/GM concentration per voxel. To avoid the overlap between GM and WM signal in the border of GM and WM (due to a combination of partial volume effect and smoothing of the maps), we removed 3 voxels on the border of the GM and WM regions.

\subsection{Statistical analyses}

Repeated-measures ANOVA or Student's paired $t$-tests were performed to examine changes in adiposity, metabolic and inflammatory measurements after SG. Linear mixed-effects models were used to assess WM and GM changes following SG, with session (baseline, 4 months, or 12 months) as a fixed factor and subject as a random factor. Age, sex, initial BMI, and baseline diabetic status were included in the model as covariates. The mixed-effects model estimates are represented by Beta values in the results section. VBM results were whole-brain False Discovery Rate (FDR) corrected ( $\mathrm{p}<0.05$ ). To examine the associations with adiposity, metabolic and inflammatory variables, and surgery-induced brain changes in GM or WM density, the AAL Atlas (Tzourio-Mazoyer et al., 2002) was used to extract average regional VBM GM values and similarly, the Atlas from Yeh et al. (2018) was used to extract regional VBM WM values for each participant. Mean GM and WM densities were extracted across all the participants. Linear mixed-effects models were used to assess the association between changes in adiposity, metabolism, and inflammation and changes in GM or WM density (dependent variables). Age and sex were included in the model as covariates. All continuous variables were z-scored prior to the analysis. The Bonferroni correction was applied for multiple comparisons. Linear mixed-effect models were fitted using fitlme from MATLAB version R2017a (The MathWorks Inc., Natick, MA). Other statistical analyses were performed with JMP software version 14 (SAS Institute Inc, Cary, NC, USA).

\subsection{Validation in an independent dataset from the Human Connectome Project}

We used an independent sample from the Human Connectome Project (HCP) to test whether the WM and GM regions that significantly changed after the surgery show BMI-related differences in participants who are obese versus normal weight in a separate adult population (Van Essen et al., 2012). All the participants from the HCP with a BMI higher than 35 $\mathrm{kg} / \mathrm{m}^{2}$ were included in the study. These participants $(\mathrm{n}=46)$ were individually matched (1:1) for age, sex, and ethnicity with a group of HCP individuals who had a normal body weight $(n=46)$. Other exclusion criteria included participants with missing information on age, sex, BMI, and ethnicity. T1-weighted 3D MPRAGE sequence with $0.7 \mathrm{~mm}$ isotropic resolution images were acquired by the HCP investigators using a 3T MRI scanner (Siemens Skyra) equipped with a 32-channel head coil. The following parameters were used: 256 sagittal slices in a single slab, $\mathrm{TR} / \mathrm{TE}=2400 \mathrm{~ms} / 2.14 \mathrm{~ms}, \mathrm{~T} 1=1000 \mathrm{~ms}$, field of view $(\mathrm{FOV})=224$ $\mathrm{mm}, \mathrm{FA}=8^{\circ}$, Echo Spacing $=7.6 \mathrm{~ms}$, and voxel size $=0.7 \times 0.7 \times 0.7$ $\mathrm{mm}^{3}$ (Glasser et al., 2013). GM and WM VBM were calculated using the same procedure as in our clinical sample. Student's paired $t$-tests were used to compare peak VBM values of the regions that significantly changed after surgery in our sample between HCP participants who were severely obese versus normal weight. 


\section{Results}

\subsection{Clinical characteristics of participants}

Clinical characteristics of study participants are shown in Table 1. As expected, weight, BMI, and waist circumference significantly decreased 4 months and 12 months after SG compared with baseline ( $\mathrm{p}<0.0001$ for all). The mean \%EWL was $46.7 \pm 10.3$ after 4 months and $68.1 \pm 13.4$ after 12 months. The mean \%TWL was $21.3 \pm 4.3$ after 4 months and $31.1 \pm 5.4$ after 12 months. At baseline, the study sample included 21 participants who were non-diabetic and 8 who were diabetic. As expected from bariatric surgery, type 2 diabetes was cured in $25 \%(2 / 8)$ and improved in 75\% (6/8) 4 months post-surgery. At 12 months, type 2 diabetes was cured in $63 \%$ (5/8) and improved in 37\% (3/8). Significant improvements in blood pressure, glucose homeostasis, HDL-cholesterol, and triglyceride levels as well as circulating inflammatory markers (CRP, IL-6 and LBP) were observed after surgery (Table 1).

Measurements of eating behavior prior to and after surgery are shown in Table S1. The mean BES score, the number of dimensions of the YFAS, and the mean PFS scores were significantly reduced after the surgery ( $p$ $<0.05$, for all). Some traits of the FCQ were significantly reduced after the surgery, such as hunger and environment ( $\mathrm{p}<0.05$, for both). The disinhibition score was significantly increased after the surgery $(\mathrm{p}=$

Table 1

Characteristics of participants at baseline, 4 and 12 months after SG.

\begin{tabular}{|c|c|c|c|c|}
\hline & Baseline & 4 months & $\begin{array}{l}12 \\
\text { months }\end{array}$ & $p$ value \\
\hline$N$ & 29 & 27 & 17 & \\
\hline Sex (F: M) & $21: 8$ & 19:8 & $13: 4$ & - \\
\hline Diabetes (Y: N) & $8: 21$ & & & - \\
\hline Age (years) & $45.9 \pm 7.8$ & & & \\
\hline Weight (kg) & $\begin{array}{l}122.4 \pm \\
16.2\end{array}$ & $\begin{array}{l}95.5 \pm \\
13.2\end{array}$ & $\begin{array}{l}82.6 \pm \\
13.3\end{array}$ & $\begin{array}{l}<0.0001^{\mathrm{a}} \mathrm{F}= \\
176.2\end{array}$ \\
\hline BMI $\left(\mathrm{kg} / \mathrm{m}^{2}\right)$ & $44.1 \pm 4.6$ & $\begin{array}{l}34.2 \pm \\
3.9\end{array}$ & $\begin{array}{l}29.8 \pm \\
3.7\end{array}$ & $\begin{array}{l}<0.0001^{\mathrm{a}} \mathrm{F}= \\
243.5\end{array}$ \\
\hline $\begin{array}{l}\text { Waist circumference } \\
(\mathrm{cm})\end{array}$ & $132 \pm 12$ & $113 \pm 11$ & $103 \pm 12$ & $\begin{array}{l}<0.0001^{\mathrm{a}} \mathrm{F}= \\
85.6\end{array}$ \\
\hline $\begin{array}{l}\text { Neck circumference } \\
(\mathrm{cm})\end{array}$ & $42 \pm 4$ & $37 \pm 4$ & $36 \pm 3$ & $\begin{array}{l}<0.0001^{\mathrm{a}} \mathrm{F}= \\
122.8\end{array}$ \\
\hline EWL (\%) & - & $\begin{array}{l}46.7 \pm \\
10.3\end{array}$ & $\begin{array}{l}68.1 \pm \\
13.4\end{array}$ & $\begin{array}{l}<0.0001^{\mathrm{b}} \mathrm{T}= \\
11.5\end{array}$ \\
\hline TWL (\%) & - & $\begin{array}{l}21.3 \pm \\
4.3\end{array}$ & $\begin{array}{l}31.1 \pm \\
5.4\end{array}$ & $\begin{array}{l}<0.0001^{\mathrm{b}} \mathrm{T}= \\
11.0\end{array}$ \\
\hline $\begin{array}{l}\text { Systolic blood pressure } \\
(\mathrm{mmHg})\end{array}$ & $144 \pm 17$ & $124 \pm 12$ & $120 \pm 16$ & $\begin{array}{l}0.001^{\mathrm{a}} \mathrm{F}= \\
11.7\end{array}$ \\
\hline $\begin{array}{l}\text { Diastolic blood pressure } \\
\text { (mmHg) }\end{array}$ & $87 \pm 11$ & $76 \pm 11$ & $71 \pm 8$ & $\begin{array}{l}<0.0001^{\mathrm{a}} \mathrm{F}= \\
37.6\end{array}$ \\
\hline $\begin{array}{l}\text { Fasting glycemia } \\
\quad(\mathrm{mmol} / \mathrm{L})\end{array}$ & $6.4 \pm 1.1$ & $4.8 \pm 0.8$ & $4.8 \pm 1.1$ & $\begin{array}{l}0.0006^{\mathrm{a}} \mathrm{F}= \\
12.9\end{array}$ \\
\hline Fasting insulin (mU/L) & $\begin{array}{l}15.5 \pm \\
10.7\end{array}$ & $6.1 \pm 3.6$ & $4.9 \pm 3.5$ & $\begin{array}{l}0.001^{\mathrm{a}} \mathrm{F}= \\
11.0\end{array}$ \\
\hline HOMA-IR index & $4.6 \pm 4.0$ & $1.4 \pm 1.0$ & $1.2 \pm 1.3$ & $0.002^{\mathrm{a}} \mathrm{F}=9.6$ \\
\hline $\begin{array}{l}\text { Total cholesterol } \\
\text { (mmol/L) }\end{array}$ & $4.9 \pm 1.1$ & $4.1 \pm 1.1$ & $4.5 \pm 1.0$ & $0.23^{\mathrm{a}} \mathrm{F}=1.7$ \\
\hline $\begin{array}{l}\text { LDL-cholesterol (mmol/ } \\
\text { L) }\end{array}$ & $3.6 \pm 1.1$ & $2.8 \pm 1.1$ & $3.0 \pm 1.0$ & $0.37^{\mathrm{a}} \mathrm{F}=1.1$ \\
\hline $\begin{array}{l}\text { HDL-cholesterol } \\
\text { (mmol/L) }\end{array}$ & $1.3 \pm 0.3$ & $1.2 \pm 0.3$ & $1.5 \pm 0.4$ & $0.003^{\mathrm{a}} \mathrm{F}=8.5$ \\
\hline Triglycerides (mmol/L) & $1.8 \pm 0.9$ & $1.3 \pm 0.5$ & $1.1 \pm 0.4$ & $\begin{array}{l}0.0005^{\mathrm{a}} \mathrm{F}= \\
13.4\end{array}$ \\
\hline CRP (mg/L) & $7.5 \pm 5.7$ & $3.0 \pm 2.6$ & $1.5 \pm 1.5$ & $0.002^{\mathrm{a}} \mathrm{F}=9.6$ \\
\hline IL-6 (ng/ml) & $2.9 \pm 2.1$ & $2.0 \pm 1.7$ & $1.5 \pm 0.9$ & $0.02^{\mathrm{a}} \mathrm{F}=5.9$ \\
\hline LBP (ug/ml) & $13.6 \pm 3.3$ & $\begin{array}{l}12.4 \pm \\
2.6\end{array}$ & $\begin{array}{l}11.8 \pm \\
1.8\end{array}$ & $\begin{array}{l}<0.0001^{\mathrm{a}} \mathrm{F}= \\
28.7\end{array}$ \\
\hline
\end{tabular}

Results are presented as mean $\pm \mathrm{SD}$.

BMI, body mass index; EWL \%, excess weight loss percentage; TWL \%, total weight loss percentage; CRP, C-reactive protein; IL-6, interleukin-6; LBP, lipopolysaccharide-binding protein.

a Repeated measures ANOVA comparing baseline, 4 months and 12 months post-surgery sessions.

b Paired t-tests comparing 4 months and 12 months post-surgery sessions.
0.006), while no change was observed for the dietary restraint and susceptibility to hunger scores. Hunger levels prior to and after the MRI session were similar at baseline, 4 months, and 12 months. Hunger levels after the MRI session were higher compared to hunger levels prior to the MRI session at each visit $(\mathrm{F}=55.5, \mathrm{p}<0.0001)$.

\subsection{Effect of $S G$ on $W M$ and $G M$ density}

Fig. 1 shows the Beta value maps from the voxel-wise mixed effectsmodels for the WM regions that were significant after FDR correction ( $p$ $<0.05$ ). A widespread increase in WM density was observed 4 months after SG compared to baseline. These significant increases were found in the cerebellum and cerebellar peduncle but also in the brain stem extending up to cerebral peduncle. There was also a diffuse increase in WM density in the corpus callosum and cingulum projecting out to the corona radiata. Twelve months after the surgery, greater and more significant WM density increases were found compared to baseline in the same significant WM regions observed after the first 4 months, suggesting more pronounced changes after 12 months (Fig. 1). As expected, significant WM density increases were observed 12 months post-surgery compared to 4 months post-surgery in the same brain regions ( $\mathrm{p}<$ 0.05, after FDR correction, Fig. S1).

Fig. 2 shows the Beta value maps from the voxel-wise mixed effectsmodels for the GM regions that were significant after FDR correction (p $<0.05$ ). Significant increases in GM density were observed 4 months after SG compared to baseline in several brain regions such as the bilateral occipital cortex, temporal cortex, postcentral gyrus, cerebellum, hippocampus, and insula as well as right fusiform gyrus, right parahippocampal gyrus, right lingula gyrus, and right amygdala (Fig. 2, Table S2). Twelve months after SG, greater increases in GM density were found compared to baseline in cortical and subcortical brain regions including bilateral occipital and temporal cortex, precentral gyrus, postcentral gyrus, frontal operculum cortex, fusiform gyrus, insula, parahippocampal gyrus, lingula gyrus, cerebellum, amygdala, hippocampus, putamen, caudate nucleus, and thalamus (Fig. 2, Table S3). Two regions showed slightly decreased GM density after SG (left cerebellum and right precuneus cortex). No significant difference was observed in GM density comparing the 12-month and the 4-month post-surgery sessions (data not shown).

\subsection{Associations between changes in WM density and adiposity, metabolic and inflammatory markers following $S G$}

Mixed-effects models were performed to assess the associations between changes in WM density and adiposity, metabolic, or inflammatory variables after SG, accounting for age and sex. Significant associations were found between post-operative reduction in BMI, waist circumference, or neck circumference and increased WM density in the cingulum and cerebellar peduncle ( $\mathrm{p} \leq 0.0001$ for all, Table S4). A significant association was also observed between post-operative BMI loss and increased WM density in the parietopontine tract ( $p=0.0016$, Table S4). Reduced insulin levels following SG were significantly associated with increases in several WM regions such as the acoustic radiation, cingulum, extreme capsule, cerebellar peduncle, occipitopontine tract, and parietopontine tract ( $\mathrm{p} \leq 0.0002$ for all, Table S6). The same results were observed with the HOMA-IR index. Our linear mixed-effect models showed significant positive associations between HDL-cholesterol levels and WM density in acoustic radiation, extreme capsule, occipitopontine tract, parietopontine tract, anterior commissure, arcuate fasciculus, corpus callosum, and corticothalamic pathway ( $\mathrm{p} \leq 0.0011$ for all, Table S6). No significant association was found between WM density and circulating levels of glucose, LDL-cholesterol, and triglycerides (data not shown). Strong associations were observed between post-operative reductions in LBP and increased WM density in the cingulum, corticospinal tract, extreme capsule, cerebellar peduncle, occipitopontine tract, parietopontine tract, and spinothalamic tract $(\mathrm{p} \leq 0.0017$, Fig. 3 and 

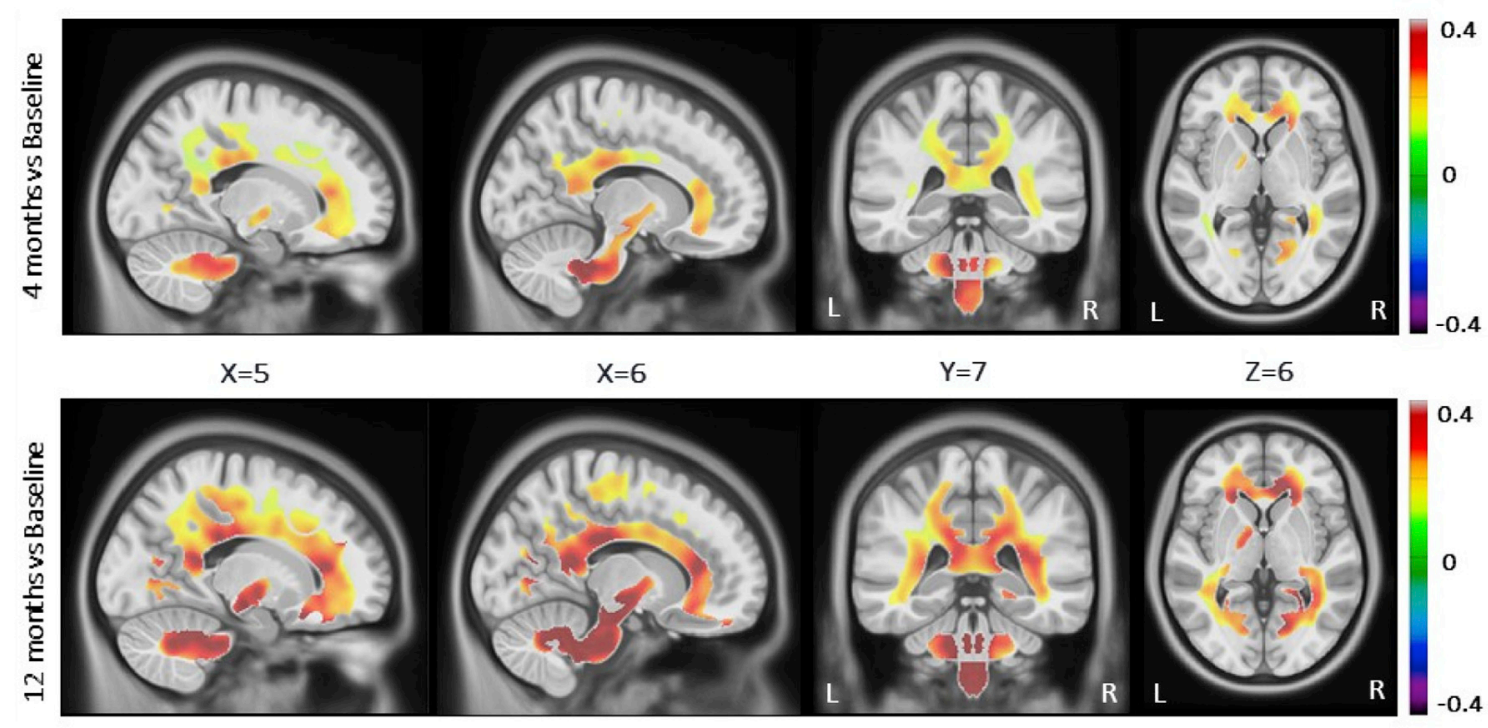

Fig. 1. Widespread increase in white matter (WM) density 4 months or 12 months post-surgery compared to baseline. The figure shows the Beta value maps from the voxel-wise mixed-effects models, for the WM regions that were significant after whole brain FDR correction ( $\mathrm{p}<0.05)$. Colors show higher positive (in red) or negative (in dark purple) Beta values. These results were significant after correcting for age, sex, initial BMI and diabetic status. L, left; R, right.
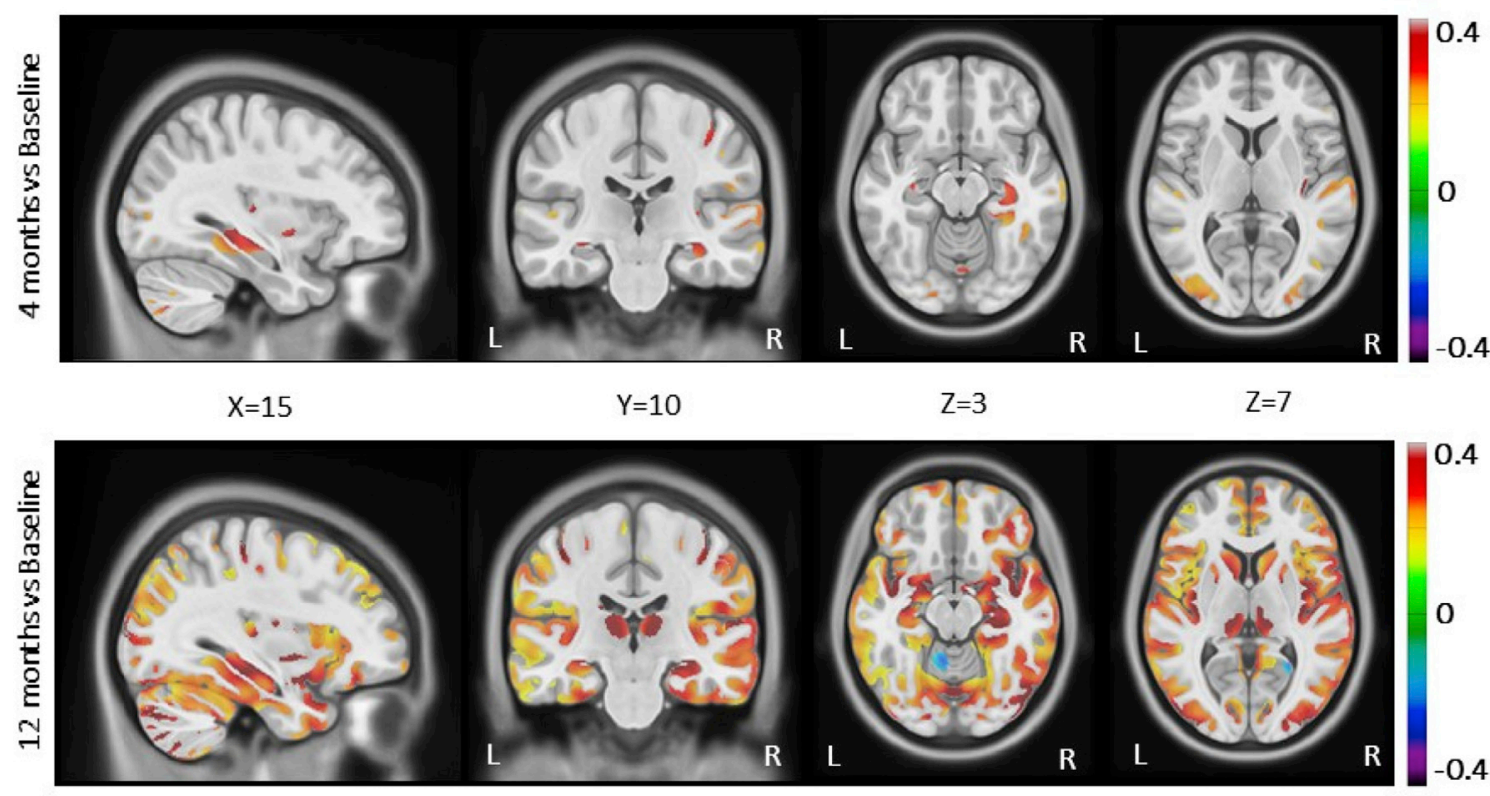

Fig. 2. Changes in grey matter (GM) density 4 months or 12 months post-surgery compared to baseline. The figure shows the Beta value maps from the voxel-wise mixed-effects models, for the GM regions that were significant after whole brain FDR correction ( $<<0.05$ ). Colors show higher positive (in red) or negative (in dark purple) Beta values. These results were significant after correcting for age, sex, initial BMI and diabetic status. L, left; R, right.

Table S8). Decreased plasma IL-6 concentrations were significantly related to increased WM density in cerebellar peduncle and spinothalamic tract ( $\mathrm{p} \leq 0.0012$, Table S8). No significant Bonferroni-corrected associations were found between CRP levels and WM density (Table S8).

\subsection{Associations between changes in GM density and adiposity, metabolic, or inflammatory markers following $S G$}

Mixed-effects models were also performed to examine the associations between changes in GM density and adiposity, metabolic, or inflammatory variables following SG, accounting for age and sex. Strong associations were observed between post-operative BMI, waist circumference, or neck circumference reduction and increased GM density in several cortical and subcortical regions including the precentral gyrus, inferior frontal gyrus, rolandic operculum, insula, hippocampus, amygdala, occipital cortex, fusiform gyrus, angular gyrus, putamen, heschl, temporal cortex, cerebellum, and parahipoccampal gyrus ( $\mathrm{p} \leq 0.0009$, Table S5). Significant negative associations were found between fasting glucose levels and GM density in bilateral occipital cortex, putamen and cerebellum ( $\mathrm{p} \leq 0.0006$, Table S7). Post-operative reductions in insulin levels were significantly associated with increased GM density in the inferior frontal gyrus and rolandic operculum ( $\mathrm{p} \leq 0.0013$, Table S7). Post-surgery decreases in triglyceride levels were significantly related to GM density in precentral gyrus, rolandic operculum, supplementary motor area, amygdala, occipital cortex, fusiform gyrus, postcentral gyrus, angular gyrus, temporal cortex, and cerebellum ( $\leq 0.0013$, Table S7). 


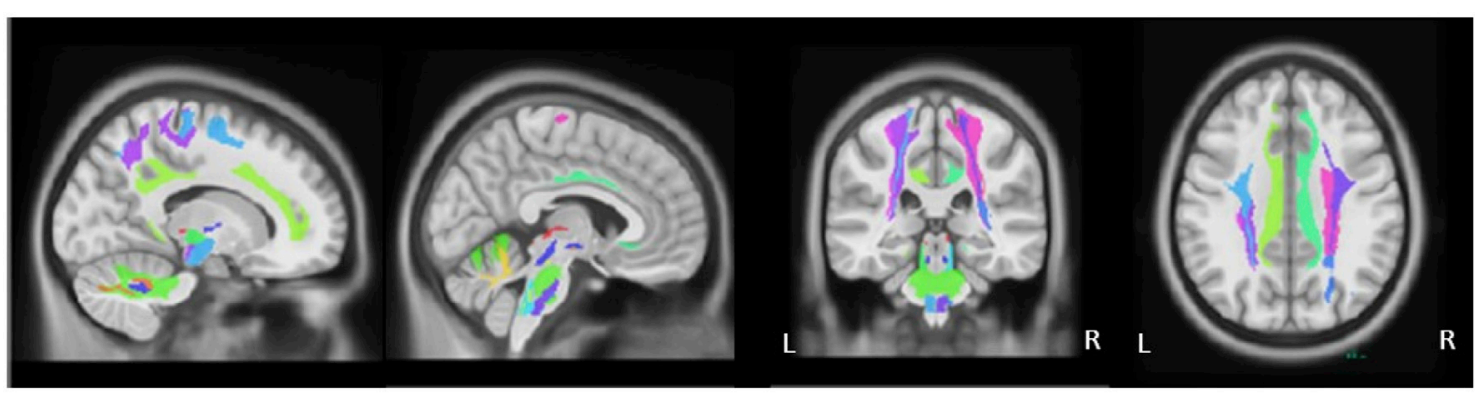

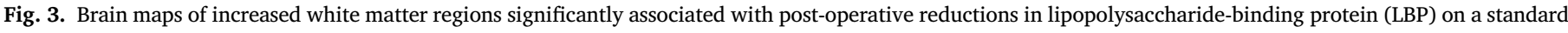

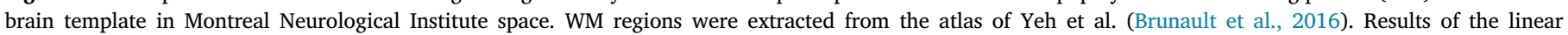
mixed-effect models are presented in Table S5. L, left; R, right.

No significant association was observed between changes in GM density and circulating levels of HDL-cholesterol, LDL-cholesterol, LBP, IL-6, CRP and HOMA-IR index (data not shown).

\subsection{Effect of obesity on WM and GM density: Validation in an independent dataset}

To confirm that our results lie in brain areas that are relevant for severe obesity, we used an independent dataset from the HCP. We tested whether the peak of each WM and GM region that significantly increased after the surgery shows BMI-related differences in a separate population. We matched a group of 46 individuals who were severely obese (BMI: $38.0 \pm 2.8 \mathrm{~kg} / \mathrm{m}^{2}$ ) with a group of 46 who were lean (BMI: $22.2 \pm 1.3 \mathrm{~kg}$ / $\mathrm{m}^{2}$ ) for age, sex, and ethnicity (Table 2). Mean age was 28.9 years in both groups and most of the individuals were Caucasian (72\%). The most significant regions in WM from our clinical sample, such as the brain stem and cerebellar peduncle, had significantly reduced density in those who were obese compared with their lean counterparts (Fig. 4, p < 0.0001). GM density in the two regions of the cerebellum was significantly reduced in obese individuals relative to controls (Fig. 5, p $<0.0001$ ). To ensure the robustness of the results, mean VBM values were also calculated in a spherical region with each peak as the centre and a radius of 2 $\mathrm{mm}$ and the analysis was repeated, achieving the same results (data not shown).

\section{Discussion}

Bariatric surgery and concomitant weight loss were associated with diffusely increased GM and WM density. The increases were more prominent in spatial extent and amount for WM than GM. The increases were diffusely present in the brain 4 months post-operatively and more pronounced and widespread after 12 months. Moreover, these changes were related to improvement in inflammatory and metabolic measurements. The linear mixed-effect model showed an especially clear association between post-operative reductions in LBP, a marker of inflammation, and increased WM density. Furthermore, using

Table 2

Characteristics of participants who were severely obese or normal weight.

\begin{tabular}{llll}
\hline & Severely obese group & Normal weight group & $p$ value \\
\hline$N$ & 46 & 46 & - \\
Sex (F: M) & $26: 20$ & $26: 20$ & NS \\
Age (years) & $28.9 \pm 3.6$ & $28.9 \pm 3.3$ & NS \\
BMI $\left(\mathrm{kg} / \mathrm{m}^{2}\right)$ & $38.0 \pm 2.8$ & $22.2 \pm 1.3$ & $<0.0001$ \\
Ethnicity & & & \\
Caucasian $(N)$ & 33 & 33 & NS \\
African american $(N)$ & 13 & 13 & NS \\
\hline
\end{tabular}

Results are presented as mean $\pm \mathrm{SD}$; Matched paired $t$-tests comparing both groups; BMI, body mass index. independent data from the HCP, we demonstrated that the post-operative brain changes seen here were in brain areas that also showed structural alterations in a separate group with obesity, supporting the notion that these WM and GM changes represent a form of recovery.

Other groups (Tuulari et al., 2016; Rullmann et al., 2018; Zhang et al., 2016) have also recently reported that bariatric surgery-induced weight loss is associated with increased global WM density, particularly in the cerebellum, brain stem, cerebellar peduncle, cingulum, corpus callosum, and corona radiata. Imaging studies in humans show that individuals with obesity have reduced tissue density and integrity in numerous WM tracts, including the corpus callosum, cingulum, cerebellar peduncle, and corona radiata (Tuulari et al., 2016; Kullmann et al., 2015, 2016; Alfaro et al., 2018; Verstynen et al., 2013; Zhang et al., 2016; Papageorgiou et al., 2017). These findings are consistent with our current results and further support the interpretation that weight loss and concomitant improvement of metabolic alterations might reverse obesity-related WM tissue abnormalities.

Although the changes in GM density were smaller, they also go in the direction of recovery of obesity-associated brain atrophy. We observed GM increases after surgery in cortical and subcortical regions, mostly in the occipital and temporal/medial temporal lobes (e.g. hippocampus, amygdala, and parahippocampal gyrus), precentral gyrus, inferior frontal gyrus, insula, putamen, and cerebellum. As for WM, some changes were detected 4 months following surgery, but they were more extensive after 12 months, and they correlated with the magnitude of weight loss. Our results are consistent with previous bariatric surgery studies (Tuulari et al., 2016; Rullmann et al., 2018; Zhang et al., 2016) and weight-loss intervention studies (Mueller et al., 2015; Prehn et al., 2017). Both a recent meta-analysis and studies with large samples have demonstrated reduced GM volumes in obesity in several brain regions, including medial prefrontal cortex, inferior frontal gyrus (including insula), cerebellum, temporal lobe (e.g. hippocampal/parahippocampal regions and amygdala), precentral gyrus, and inferior parietal cortex (Garcia-Garcia et al., 2019; Herrmann et al., 2019; Weise et al., 2017; Vainik et al., 2018).

Our findings suggest that changes in WM/GM density after surgery are linked to improvements in cardiometabolic health. More specifically, increases in WM and GM densities were associated with post-operative improvement in glucose homeostasis (fasting insulin and glucose or HOMA-IR index), increased plasma HDL-cholesterol, and decreased triglycerides. These results are consistent with previous studies showing that insulin resistance negatively affects brain function and structure, which may contribute to cognitive impairment (Heni et al., 2015; Cheke et al., 2017). There is also some evidence linking dyslipidemia and abnormal lipid metabolism with global and regional GM or WM atrophy or WM hyperintensities (Alfaro et al., 2018). Even if the specific contribution of each metabolic change cannot be established in the present study, our results suggest that improvements of glucose homeostasis and dyslipidemia following weight-loss might reverse obesity-related WM and GM volume alterations.

Another feature of the obesity-related metabolic syndrome, chronic 

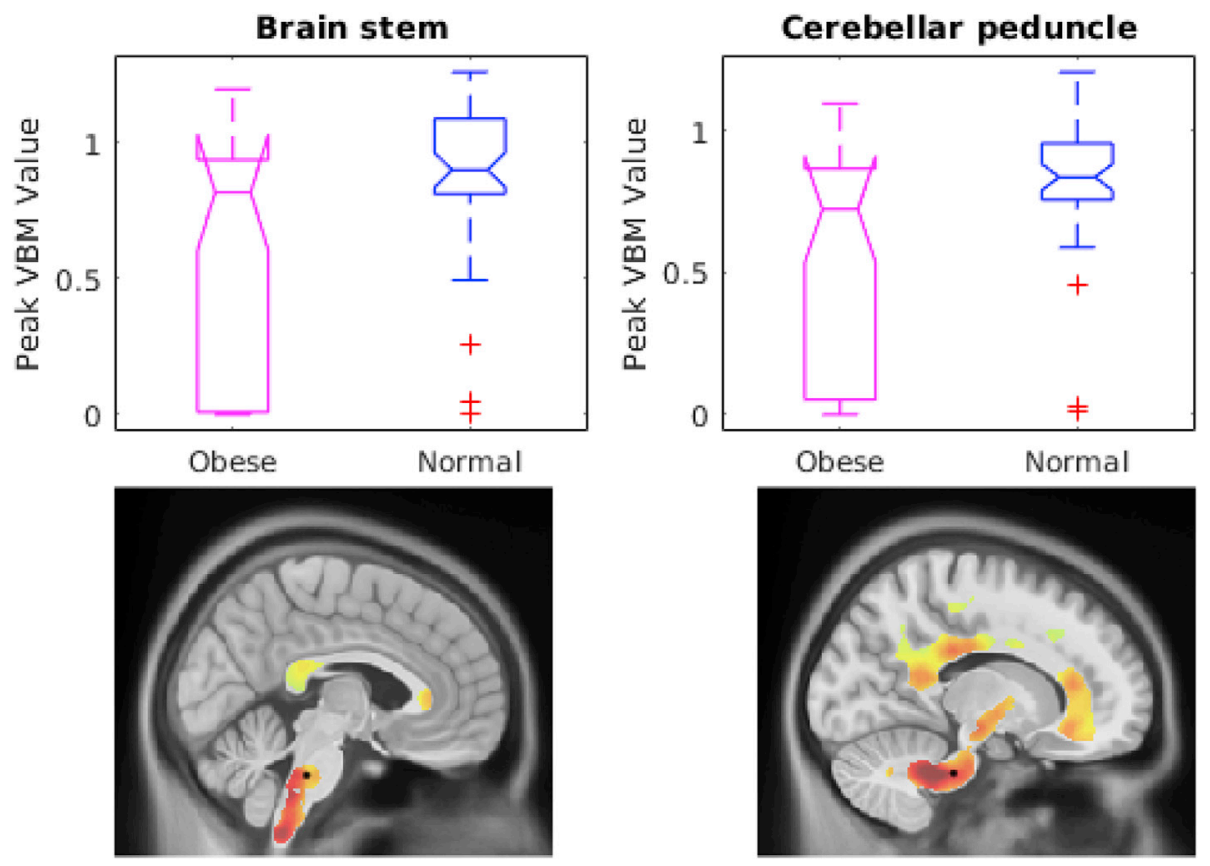

Fig. 4. Comparison of the peak Beta value in brain stem and cerebellar peduncle between individuals with severe obesity and those who had normal body weight (p $<$ 0.0001). These white matter (WM) regions were significantly increased after bariatric surgery. The localisation of the peak value is identified with a dot on the Beta maps.
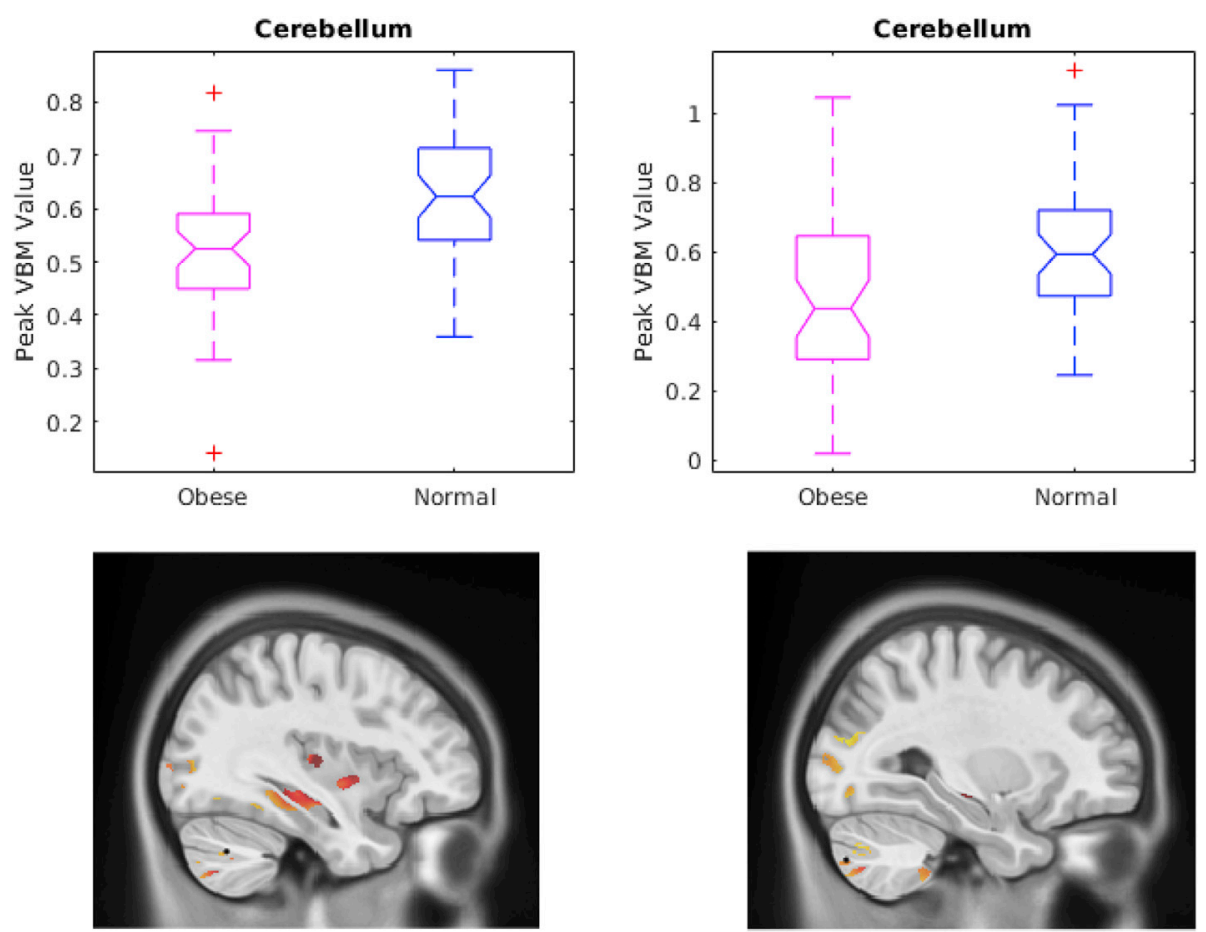

Fig. 5. Comparison of the peak Beta value in cerebellum between individuals with severe obesity and those who had normal body weight (p $<0.0001$ ). These grey matter (GM) regions were significantly increased after bariatric surgery. The localisation of the peak value is identified with a dot on the Beta value maps.

low-grade inflammation may cause obesity-induced WM alterations (Alfaro et al., 2018; Verstynen et al., 2013; Guillemot-Legris and Muccioli, 2017; Moreno-Navarrete et al., 2017). More specifically, a recent study has shown that circulating LBP level, a marker of metabolic endotoxemia (Laugerette et al., 2014), is associated with decreased integrity in some WM regions and altered cognitive performance in obesity (Moreno-Navarrete et al., 2017). In the present study, we found significant reductions in circulating LBP, IL-6 and CRP levels after bariatric surgery, which is consistent with previous studies (Yang et al., 2014; Lindegaard et al., 2015). Moreover, we report an association between post-operative reductions in LBP and increased WM density in several regions, including brain stem, cerebellum, cerebral peduncle, cingulum, and extreme capsule. Less robust associations were generally observed for IL- 6 and no significant association for CRP. A recent study reported that circulating CRP and IL- 6 levels were associated with reduced GM and WM volumes in participants who were non-demented 
and elderly (Gu et al., 2017). Even if recent evidence supports the presence of neuroinflammation in the hippocampus, amygdala, cortex and cerebellum in obesity (Guillemot-Legris and Muccioli, 2017), our study revealed no significant association between changes in GM density and postoperative reduction in inflammatory markers, possibly because GM effects of surgery were more modest, and may take longer than one year to fully manifest. As previously suggested (Tuulari et al., 2016), it is possible that WM is more vulnerable to metabolic stress and inflammation associated with obesity. Our findings raise the possibility that changes in inflammation and metabolic factors following bariatric surgery improve WM structure, which may contribute, in part, to the improvement in cognitive functions observed after surgery-induced weight loss (Alosco et al., 2014; Handley et al., 2016).

The mechanism of altered WM and GM density following bariatric surgery is unknown. Previous authors have proposed that the WM volume changes seen within the first year post-operatively represent a recovery of WM disruption (Tuulari et al., 2016; Zhang et al., 2016) or plasticity (Rullmann et al., 2018), but it is not possible to say whether WM remodeling or remyelination can occur this rapidly after surgery. Another potential mechanism is an improvement in cerebral blood flow. Studies have consistently shown that bariatric surgery may ameliorate cerebral blood flow by reducing carotid artery atherosclerosis (Gomez-Martin et al., 2017) and improving flow-mediated arterial dilation (Lupoli et al., 2016). Cerebral blood oxygen concentration and blood volume can both affect $\mathrm{T} 1$ signal and lead to changes in estimated grey mater volume and cortical thickness (Tardif et al., 2017). Furthermore, improved cerebrovascular function and tissue might lead to axon sprouting, dendritic changes, myelin formation or remodeling, synaptic changes or glial changes, all brain components that may influence MRI signals (Zatorre et al., 2012; Wenger et al., 2017). Finally, it has been shown that chronic inflammation may impact WM (Alfaro et al., 2018; Verstynen et al., 2013; Guillemot-Legris and Muccioli, 2017; Bettcher et al., 2013). It also bears noting that chronic elevation in plasma inflammatory markers is prospectively associated with WM disruption in otherwise healthy adults (Walker et al., 2017). Interestingly, Rullman et al. provided evidence from diffusion weighted MRI that increased WM density after surgery may reflect changes in the composition of fiber tracts (Rullmann et al., 2018).

Some limitations of the study should be acknowledged. The crosssectional population from the HCP used to validate our results was younger and did not include participants with metabolic comorbidities, which may have reduced the significant brain difference observed between the normal weight and severely obese groups. Also, we do not have an age-matched control group (non-surgical, non-obese). Another limitation is that no MRI measures of WM integrity (e.g. diffusion imaging) were included in the current study. The fact that all body composition and metabolic and inflammatory measures covary with one another means it is not possible to specify which of these is responsible for recovery of GM and WM density.

In conclusion, bariatric surgery-induced weight loss and improvement in metabolic alterations is associated with widespread increases in WM and GM densities. These post-operative changes overlapped with brain differences between severe obesity and normal-weight, which may suggest a recovery of WM and GM alterations after bariatric surgery. Our results also raise the possibility that changes in inflammation or metabolic factors following bariatric surgery improve WM and GM structure. Moreover, in addition to prior work, these findings lend support for bariatric surgery having specific benefits for brain health in individuals with severe obesity.

\section{Funding}

This study is supported by a Team grant from the Canadian Institutes of Health Research (CIHR) on bariatric care (TB2-138776) and an Investigator-initiated study grant from Johnson \& Johnson Medical Companies (Grant ETH-14-610). Funding sources for the trial had no role in the design, conduct or management of the study, in data collection, analysis or interpretation of data, or in the preparation of the present manuscript and decision to publish. A.M. and I.G.G. are recipients of postdoctoral fellowships from the Canadian Institutes of Health Research. The Co-investigators and collaborators of the REMISSION study are (alphabetical order): Bégin C, Biertho L, Bouvier M, Biron S, Cani P, Carpentier A, Dagher A, Dubé F, Fergusson A, Fulton S, Hould FS, Julien $\mathrm{F}$, Kieffer $\mathrm{T}$, Laferrère $\mathrm{B}$, Lafortune $\mathrm{A}$, Lebel $\mathrm{S}$, Lescelleur $\mathrm{O}$, Levy $\mathrm{E}$, Marette A, Marceau S, Michaud A, Picard F, Poirier P, Richard D, Schertzer J, Tchernof A, Vohl MC.

\section{Declaration of competing interest}

A. T. and L.B. are recipients of research grant support from Johnson \& Johnson Medical Companies and Medtronic for studies on bariatric surgery and the Research Chair in Bariatric and Metabolic Surgery at IUCPQ and Laval University, respectively. No author declared a conflict to interest relevant to the content of the manuscript.

\section{Acknowledgments}

We would like to acknowledge the contribution of surgeons, nurses, the medical team of the bariatric surgery program at IUCPQ, MRI technicians, Xavier Moreel, Coordinator of the Plateforme d'imagerie avancée at IUCPQ, and Guillaume Gilbert, Engineer, Phillips as well as the collaboration of participants. We would like to acknowledge the help of Marie-Frédérique Gauthier for the measurement of cytokines.

\section{Appendix A. Supplementary data}

Supplementary data to this article can be found online at https://doi. org/10.1016/j.neuroimage.2020.116696.

\section{References}

Albanese, E., Launer, L.J., Egger, M., Prince, M.J., Giannakopoulos, P., Wolters, F.J., et al., 2017. Body mass index in midlife and dementia: systematic review and metaregression analysis of 589,649 men and women followed in longitudinal studies. Alzheimers Dement (Amst) 8, 165-178.

Alfaro, F.J., Gavrieli, A., Saade-Lemus, P., Lioutas, V.A., Upadhyay, J., Novak, V., 2018. White matter microstructure and cognitive decline in metabolic syndrome: a review of diffusion tensor imaging. Metabolism 78, 52-68.

Alosco, M.L., Galioto, R., Spitznagel, M.B., Strain, G., Devlin, M., Cohen, R., et al., 2014. Cognitive function after bariatric surgery: evidence for improvement 3 years after surgery. Am J Surg 207 (6), 870-876.

Bettcher, B.M., Walsh, C.M., Watson, C., Miller, J.W., Green, R., Patel, N., et al., 2013. Body mass and white matter integrity: the influence of vascular and inflammatory markers. Plos One 8 (10), e77741.

Biertho, L., Biron, S., Hould, F.S., Lebel, S., Marceau, S., Marceau, P., 2010. Is biliopancreatic diversion with duodenal switch indicated for patients with body mass index $<50 \mathrm{~kg} / \mathrm{m} 2$ ? Surg. Obes. Relat. Dis. 6 (5), 508-514.

Biertho, L., Simon-Hould, F., Marceau, S., Lebel, S., Lescelleur, O., Biron, S., 2016. Current outcomes of laparoscopic duodenal switch. Ann. Surg Innovat. Res. 10, 1.

Brunault, P., Gaillard, P., Ballon, N., Couet, C., Isnard, P., Cook, S., et al., 2016. [Validation of the French version of the Binge Eating Scale: examination of its factor structure, internal consistency and construct validity in a non-clinical and a clinical population]. Encephale 42 (5), 426-433.

Brunault, P., Courtois, R., Gearhardt, A.N., Gaillard, P., Journiac, K., Cathelain, S., et al., 2017. Validation of the French version of the DSM-5 Yale food addiction scale in a nonclinical sample. Can. J. Psychiatr. 62 (3), 199-210.

Cheke, L.G., Bonnici, H.M., Clayton, N.S., Simons, J.S., 2017. Obesity and insulin resistance are associated with reduced activity in core memory regions of the brain. Neuropsychologia 96, 137-149.

Collins, D.L., Neelin, P., Peters, T.M., Evans, A.C., 1994. Automatic 3D intersubject registration of MR volumetric data in standardized Talairach space. J. Comput. Assist. Tomogr. 18 (2), 192-205.

Coupe, P., Yger, P., Prima, S., Hellier, P., Kervrann, C., Barillot, C., 2008. An optimized blockwise nonlocal means denoising filter for 3-D magnetic resonance images. IEEE Trans Med Imaging 27 (4), 425-441.

Despres, J.P., Lemieux, I., 2006. Abdominal obesity and metabolic syndrome. Nature 444 (7121), 881-887.

Garcia-Garcia, I., Michaud, A., Dadar, M., Zeighami, Y., Neseliler, S., Collins, D.L., et al., 2019. Neuroanatomical differences in obesity: meta-analytic findings and their validation in an independent dataset. Int J Obes (Lond) 43 (5), 943-951.

Gastrointestinal surgery for severe obesity: national Institutes of health consensus development conference statement. Am. J. Clin. Nutr. 55 (2 Suppl. 1), 1992, 615S-9S. 
Glasser, M.F., Sotiropoulos, S.N., Wilson, J.A., Coalson, T.S., Fischl, B., Andersson, J.L., et al., 2013. The minimal preprocessing pipelines for the Human Connectome Project. Neuroimage 80, 105-124.

Gloy, V.L., Briel, M., Bhatt, D.L., Kashyap, S.R., Schauer, P.R., Mingrone, G., et al., 2013. Bariatric surgery versus non-surgical treatment for obesity: a systematic review and meta-analysis of randomised controlled trials. BMJ 347, f5934.

Gomez-Martin, J.M., Aracil, E., Galindo, J., Escobar-Morreale, H.F., Balsa, J.A., BotellaCarretero, J.I., 2017. Improvement in cardiovascular risk in women after bariatric surgery as measured by carotid intima-media thickness: comparison of sleeve gastrectomy versus gastric bypass. Surg. Obes. Relat. Dis. 13 (5), 848-854.

Gu, Y., Vorburger, R., Scarmeas, N., Luchsinger, J.A., Manly, J.J., Schupf, N., et al., 2017 Circulating inflammatory biomarkers in relation to brain structural measurements in a non-demented elderly population. Brain Behav Immun 65, 150-160.

Guillemot-Legris, O., Muccioli, G.G., 2017. Obesity-induced neuroinflammation: beyond the hypothalamus. Trends Neurosci. 40 (4), 237-253.

Haltia, L.T., Viljanen, A., Parkkola, R., Kemppainen, N., Rinne, J.O., Nuutila, P., et al., 2007. Brain white matter expansion in human obesity and the recovering effect of dieting. J. Clin. Endocrinol. Metab. 92 (8), 3278-3284.

Handley, J.D., Williams, D.M., Caplin, S., Stephens, J.W., Barry, J., 2016. Changes in cognitive function following bariatric surgery: a systematic review. Obes. Surg. 26 (10), 2530-2537.

Hankir, M.K., Seyfried, F., Miras, A.D., Cowley, M.A., 2018. Brain feeding circuits after roux-en-Y gastric bypass. Trends Endocrinol. Metabol. 29 (4), 218-237.

Hankir, M.K., Al-Bas, S., Rullmann, M., Chakaroun, R., Seyfried, F., Pleger, B., 2020. Homeostatic, reward and executive brain functions after gastric bypass surgery. Appetite 146, 104419.

Heni, M., Kullmann, S., Preissl, H., Fritsche, A., Haring, H.U., 2015. Impaired insulin action in the human brain: causes and metabolic consequences. Nat. Rev. Endocrinol. 11 (12), 701-711.

Herrmann, M.J., Tesar, A.K., Beier, J., Berg, M., Warrings, B., 2019. Grey matter alterations in obesity: a meta-analysis of whole-brain studies. Obes. Rev. 20 (3), 464-471.

Ho, A.J., Raji, C.A., Becker, J.T., Lopez, O.L., Kuller, L.H., Hua, X., et al., 2010. Obesity is linked with lower brain volume in $700 \mathrm{AD}$ and MCI patients. Neurobiol. Aging 31 (8), 1326-1339.

Karlsson, H.K., Tuulari, J.J., Hirvonen, J., Lepomaki, V., Parkkola, R., Hiltunen, J., et al., 2013. Obesity is associated with white matter atrophy: a combined diffusion tensor imaging and voxel-based morphometric study. Obesity (Silver Spring) 21 (12), 2530-2537.

Kullmann, S., Schweizer, F., Veit, R., Fritsche, A., Preissl, H., 2015. Compromised white matter integrity in obesity. Obes. Rev. 16 (4), 273-281.

Kullmann, S., Callaghan, M.F., Heni, M., Weiskopf, N., Scheffler, K., Haring, H.U., et al., 2016. Specific white matter tissue microstructure changes associated with obesity. Neuroimage 125, 36-44.

Lampe, L., Zhang, R., Beyer, F., Huhn, S., Kharabian-Masouleh, S., Preusser, S., et al., 2019. Visceral obesity relates to deep white matter hyperintensities via inflammation. Ann. Neurol. 85 (2), 194-203.

Laugerette, F., Alligier, M., Bastard, J.P., Drai, J., Chanseaume, E., Lambert-Porcheron, S. et al., 2014. Overfeeding increases postprandial endotoxemia in men: inflammatory outcome may depend on LPS transporters LBP and sCD14. Mol. Nutr. Food Res. 58 (7), 1513-1518.

Lindegaard, K.K., Jorgensen, N.B., Just, R., Heegaard, P.M., Madsbad, S., 2015. Effects of Roux-en-Y gastric bypass on fasting and postprandial inflammation-related parameters in obese subjects with normal glucose tolerance and in obese subjects with type 2 diabetes. Diabetol. Metab. Syndrome 7, 12.

Lowe, M.R., Butryn, M.L., Didie, E.R., Annunziato, R.A., Thomas, J.G., Crerand, C.E., et al., 2009. The Power of Food Scale. A new measure of the psychological influence of the food environment. Appetite 53 (1), 114-118.

Lupoli, R., Di Minno, M.N., Guidone, C., Cefalo, C., Capaldo, B., Riccardi, G., et al., 2016 Effects of bariatric surgery on markers of subclinical atherosclerosis and endothelial function: a meta-analysis of literature studies. Int J Obes (Lond). 40 (3), 395-402.

Matthews, D.R., Hosker, J.P., Rudenski, A.S., Naylor, B.A., Treacher, D.F., Turner, R.C., 1985. Homeostasis model assessment: insulin resistance and beta-cell function from fasting plasma glucose and insulin concentrations in man. Diabetologia 28 (7), 412-419.

Michaud, A., Drolet, R., Noel, S., Paris, G., Tchernof, A., 2012. Visceral fat accumulation is an indicator of adipose tissue macrophage infiltration in women. Metabolism 61 (5), 689-698.

Michaud, A., Grenier-Larouche, T., Caron-Dorval, D., Marceau, S., Biertho, L., Simard, S., et al., 2017. Biliopancreatic diversion with duodenal switch leads to better postprandial glucose level and beta cell function than sleeve gastrectomy in individuals with type 2 diabetes very early after surgery. Metabolism 74, 10-21.

Moreno-Navarrete, J.M., Blasco, G., Puig, J., Biarnes, C., Rivero, M., Gich, J., et al., 2017. Neuroinflammation in obesity: circulating lipopolysaccharide-binding protein associates with brain structure and cognitive performance. Int J Obes (Lond). 41 (11), 1627-1635.

Mueller, K., Moller, H.E., Horstmann, A., Busse, F., Lepsien, J., Bluher, M., et al., 2015. Physical exercise in overweight to obese individuals induces metabolic- and neurotrophic-related structural brain plasticity. Front. Hum. Neurosci. 9, 372.

Nijs, I.M., Franken, I.H., Muris, P., 2007. The modified Trait and State Food-Cravings Questionnaires: development and validation of a general index of food craving. Appetite 49 (1), 38-46.

Nota, M.H.C., Vreeken, D., Wiesmann, M., Aarts, E.O., Hazebroek, E.J., Kiliaan, A.J., 2020. Obesity affects brain structure and function- rescue by bariatric surgery? Neurosci. Biobehav. Rev. 108, 646-657.
Papageorgiou, I., Astrakas, L.G., Xydis, V., Alexiou, G.A., Bargiotas, P., Tzarouchi, L., et al., 2017. Abnormalities of brain neural circuits related to obesity: a Diffusion Tensor Imaging study. Magn. Reson. Imaging 37, 116-121.

Pedditizi, E., Peters, R., Beckett, N., 2016. The risk of overweight/obesity in mid-life and late life for the development of dementia: a systematic review and meta-analysis of longitudinal studies. Age Ageing 45 (1), 14-21.

Prehn, K., Jumpertz von Schwartzenberg, R., Mai, K., Zeitz, U., Witte, A.V., Hampel, D., et al., 2017. Caloric restriction in older adults-differential effects of weight loss and reduced weight on brain structure and function. Cerebr. Cortex 27 (3), 1765-1778.

Prickett, C., Brennan, L., Stolwyk, R., 2015. Examining the relationship between obesity and cognitive function: a systematic literature review. Obes. Res. Clin. Pract. 9 (2), 93-113.

Raji, C.A., Ho, A.J., Parikshak, N.N., Becker, J.T., Lopez, O.L., Kuller, L.H., et al., 2010. Brain structure and obesity. Hum. Brain Mapp. 31 (3), 353-364.

Ronan, L., Alexander-Bloch, A.F., Wagstyl, K., Farooqi, S., Brayne, C., Tyler, L.K., et al., 2016. Obesity associated with increased brain age from midlife. Neurobiol. Aging 47, 63-70.

Rullmann, M., Preusser, S., Poppitz, S., Heba, S., Hoyer, J., Schutz, T., et al., 2018. Gastric-bypass surgery induced widespread neural plasticity of the obese human brain. Neuroimage 172, 853-863.

Schauer, P.R., Kashyap, S.R., Wolski, K., Brethauer, S.A., Kirwan, J.P., Pothier, C.E., et al., 2012. Bariatric surgery versus intensive medical therapy in obese patients with diabetes. N. Engl. J. Med. 366 (17), 1567-1576.

Sjostrom, L., Peltonen, M., Jacobson, P., Sjostrom, C.D., Karason, K., Wedel, H., et al., 2012. Bariatric surgery and long-term cardiovascular events. J. Am. Med. Assoc. 307 (1), 56-65.

Sled, J.G., Zijdenbos, A.P., Evans, A.C., 1998. A nonparametric method for automatic correction of intensity nonuniformity in MRI data. IEEE Trans Med Imaging 17 (1), 87-97.

Stunkard, A.J., Messick, S., 1985. The three-factor eating questionnaire to measure dietary restraint, disinhibition and hunger. J. Psychosom. Res. 29 (1), 71-83.

Tardif, C.L., Steele, C.J., Lampe, L., Bazin, P.L., Ragert, P., Villringer, A., et al., 2017. Investigation of the confounding effects of vasculature and metabolism on computational anatomy studies. Neuroimage 149, 233-243.

Tchernof, A., Despres, J.P., 2013. Pathophysiology of human visceral obesity: an update. Physiol. Rev. 93 (1), 359-404.

Thaler, J.P., Schwartz, M.W., 2010. Minireview: inflammation and obesity pathogenesis: the hypothalamus heats up. Endocrinology 151 (9), 4109-4115.

Torres-Fuentes, C., Schellekens, H., Dinan, T.G., Cryan, J.F., 2017. The microbiota-gutbrain axis in obesity. Lancet Gastroenterol Hepatol 2 (10), 747-756.

Tuulari, J.J., Karlsson, H.K., Antikainen, O., Hirvonen, J., Pham, T., Salminen, P., et al., 2016. Bariatric surgery induces white and grey matter density recovery in the morbidly obese: a voxel-based morphometric study. Hum. Brain Mapp. 37 (11), 3745-3756.

Tzourio-Mazoyer, N., Landeau, B., Papathanassiou, D., Crivello, F., Etard, O., Delcroix, N., et al., 2002. Automated anatomical labeling of activations in SPM using a macroscopic anatomical parcellation of the MNI MRI single-subject brain. Neuroimage 15 (1), 273-289.

Vainik, U., Baker, T.E., Dadar, M., Zeighami, Y., Michaud, A., Zhang, Y., et al., 2018 Neurobehavioral correlates of obesity are largely heritable. Proc. Natl. Acad. Sci. U. S. A. 115 (37), 9312-9317.

Van Essen, D.C., Ugurbil, K., Auerbach, E., Barch, D., Behrens, T.E., Bucholz, R., et al., 2012. The Human Connectome Project: a data acquisition perspective. Neuroimage 62 (4), 2222-2231.

Verstynen, T.D., Weinstein, A., Erickson, K.I., Sheu, L.K., Marsland, A.L., Gianaros, P.J., 2013. Competing physiological pathways link individual differences in weight and abdominal adiposity to white matter microstructure. Neuroimage 79, 129-137.

Walker, K.A., Power, M.C., Hoogeveen, R.C., Folsom, A.R., Ballantyne, C.M., Knopman, D.S., et al., 2017. Midlife systemic inflammation, late-life white matter integrity, and cerebral small vessel disease. Stroke 48 (12), 3196-3202.

Walther, K., Birdsill, A.C., Glisky, E.L., Ryan, L., 2010. Structural brain differences and cognitive functioning related to body mass index in older females. Hum. Brain Mapp. 31 (7), 1052-1064.

Weise, C.M., Piaggi, P., Reinhardt, M., Chen, K., Savage, C.R., Krakoff, J., et al., 2017. The obese brain as a heritable phenotype: a combined morphometry and twin study. Int J Obes (Lond). 41 (3), 458-466.

Wenger, E., Brozzoli, C., Lindenberger, U., Lovden, M., 2017. Expansion and renormalization of human brain structure during skill acquisition. Trends Cognit. Sci. 21 (12), 930-939.

Yang, P.J., Lee, W.J., Tseng, P.H., Lee, P.H., Lin, M.T., Yang, W.S., 2014. Bariatric surgery decreased the serum level of an endotoxin-associated marker: lipopolysaccharidebinding protein. Surg. Obes. Relat. Dis. 10 (6), 1182-1187.

Yeh, F.C., Panesar, S., Fernandes, D., Meola, A., Yoshino, M., Fernandez-Miranda, J.C., et al., 2018. Population-averaged atlas of the macroscale human structural connectome and its network topology. Neuroimage 178, 57-68.

Zatorre, R.J., Fields, R.D., Johansen-Berg, H., 2012. Plasticity in gray and white: neuroimaging changes in brain structure during learning. Nat. Neurosci. 15 (4), 528-536.

Zhang, Y., Ji, G., Xu, M., Cai, W., Zhu, Q., Qian, L., et al., 2016. Recovery of brain structural abnormalities in morbidly obese patients after bariatric surgery. Int J Obes (Lond). 40 (10), 1558-1565.

Zhang, R., Beyer, F., Lampe, L., Luck, T., Riedel-Heller, S.G., Loeffler, M., et al., 2018. White matter microstructural variability mediates the relation between obesity and cognition in healthy adults. Neuroimage 172, 239-249. 